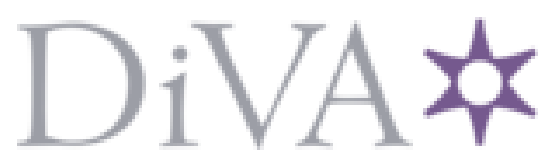

http://www.diva-portal.org

This is the published version of a paper presented at 2014 Electrochemical Conference on Energy \& the Environment (ECEE2014).

Citation for the original published paper:

$\mathrm{Bu}$, J. (2014)

Preparation of Potential Protonic Conductor Yttria Doped Hafnia by Using the Modified Solid State Reaction Method.

In: (pp. 315-320).

N.B. When citing this work, cite the original published paper.

Permanent link to this version:

http://urn.kb.se/resolve?urn=urn:nbn:se:kth:diva-165066 


\title{
Preparation of Potential Protonic Conductor Yttria Doped Hafnia by Using the Modified Solid State Reaction Method
}

\author{
Junfu Bu ${ }^{\mathrm{a}^{*}}$, Pär G. Jönsson ${ }^{\mathrm{a}}$, Zhe Zhao ${ }^{\mathrm{a}, \mathrm{b}^{*}}$ \\ ${ }^{a}$ Department of Materials Science and Engineering, KTH Royal Institute of Technology, SE- \\ 10044 Stockholm, Sweden \\ ${ }^{\mathrm{b}}$ Department of Materials Science and Engineering, Shanghai Institute of Technology, \\ 201418, Shanghai, China
}

\begin{abstract}
A pure and well crystalized yttrium doped hafnium oxide $\mathrm{Hf}_{0.69} \mathrm{Y}_{0.31} \mathrm{O}_{2-}$ ${ }_{\delta}$ (YSH) is obtained by using a modified solid state reaction method, where a water-based milling medium and freeze drying are implemented to reduce the agglomeration. The mean sizes of the YSH powder, which is obtained through a traditional alcohol-based milling method, is more than $1 \mathrm{um}$. However, the powder size can be reduced to $100 \mathrm{~nm}$ by using the water-based milling method. In addition, the calcination temperature can be lowered $200{ }^{\circ} \mathrm{C}$ to get a pure phase by using the water-based milling method, compared to the alcohol-based milling method. The relative density of YSH ceramic materials can reach to $97.5 \%$ by conventional sintering at $1650{ }^{\circ} \mathrm{C}$ after during $10 \mathrm{~h}$.
\end{abstract}

\section{Introduction}

$\mathrm{HfO}_{2}$ has a monoclinic crystal structure at room temperature. It can be considered to have a distorted cubic fluorite structure. Therefore, it can be transformed into a cubic fluorite structure by stabilizers, such as $\mathrm{CaO}, \mathrm{MgO}, \mathrm{Y}_{2} \mathrm{O}_{3}$, or rare-earth oxides (1). As the paragenetic mineral of hafnia, zirconia is already used in many different areas due its combination of mechanical, electrical, thermal and other properties (2-14). One of these typical applications is a solid oxide fuel cell electrolyte by using yttria stabilized zirconia (8YSZ). However, there exit few studies on the conductivity of hafnia-based compounds used as solid oxide fuel cells electrolyte (15-18). Even if such research exits, the research is mainly focused on the oxygen ion conductivity. None of them have investigated the potential protonic conductivity of yttria doped hafnia. However, in view of the low activation energy of protons during the transport process, there is a growing interest to explore protonic-conducting ceramics electrolytes (1921). Wagner et al. (22) first reported the protonic conductivity of a single crystal YSZ working at $1000{ }^{\circ} \mathrm{C}$. After that, several studies of the protonic conductivity were carried out on dense YSZ (23-25) and $\left(\mathrm{CeO}_{2}\right)_{0.9}\left(\mathrm{GdO}_{1.5}\right)_{0.1}(26)$ at high temperature working conditions (more than $800{ }^{\circ} \mathrm{C}$ ). However, no obvious protonic conductivity was observed. In contrast, researchers found that there is an enhanced protonic conductivity when the testing temperature is lower than $150{ }^{\circ} \mathrm{C}(27-34)$. In order to investigate the potential protonic conductivity and the relative applications of hafnia-based compounds, the compound $\mathrm{Hf}_{0.69} \mathrm{Y}_{0.31} \mathrm{O}_{2-\delta}(\mathrm{YSH})$ was synthesized in this study. In addition, the advantages of the waterbased milling method were discussed also. 


\section{Experimental}

\section{$\underline{\text { Powder synthesis }}$}

$\mathrm{HfO}_{2}$ and $\mathrm{Y}_{2} \mathrm{O}_{3}$ powders were bought from Alfa Aesar Company (Germany) with a purity of $99.99 \%$. The $70 \mathrm{~mol} . \% \mathrm{HfO}_{2}$ and $30 \mathrm{~mol} . \% \mathrm{Y}_{2} \mathrm{O}_{3}$ powders were mixed and milled in a planetary ball-mill for $10 \mathrm{~h}$. A traditional alcohol-based milling method and a water-based milling method was used in this study. In the alcohol-based milling method, isopropanol was used as the milling dispersant; in the water-based milling, deionized water, PVA, PEG, PAA and ammonia were used as the milling dispersant. Then, the mixed powder slurry was dried in a normal oven at $80{ }^{\circ} \mathrm{C}$ for the alcohol-based method, or in a freeze-drier for the water-based milling method. Thereafter, the dried powder mixture was calcined from 1300 to $1500{ }^{\circ} \mathrm{C}$. During this calcination process, a heating rate of $5{ }^{\circ} \mathrm{C} / \mathrm{min}$ and a cooling rate of $25^{\circ} \mathrm{C} / \mathrm{min}$ was always used.

\section{$\underline{\text { Sintering }}$}

The synthesized powder was milled and dried again by using the water-based milling method. All of the pellets were formed under pressures ranging from 100 to $500 \mathrm{MPa}$ and during $5 \mathrm{~min}$. After that, the pellets were sintered at a temperature of $1650{ }^{\circ} \mathrm{C}$ and during $10 \mathrm{~h}$.

\section{Characterization}

The phase purity and structure were characterized by XRD, using a Philips X'pert X-ray diffractometer equipped with a graphite monochromatized $\mathrm{Cu} K \alpha$ radiation $(\lambda=1.540598 \AA)$. The morphologies of the YSH powder and pellet were taken by a JSM-7000F scanning electron microscopy (JEOL Ltd., Japan). The relative density was calculated by the Archimedes method by using a water medium.

\section{Results and discussion}

\section{$\underline{\text { XRD analysis }}$}

As shown in Fig. 1, it is clear that the water-based milling method and the cooling rate influence the phase purity significantly. In the alcohol-based milling method, it is difficult to obtain a designed YSH compound after one milling cycle followed by calcination at a low temperature of $1300{ }^{\circ} \mathrm{C}$ (Fig. 1a) and $1400{ }^{\circ} \mathrm{C}$ (Fig. 1b). In order to obtain a pure phase, more milling and calcination cycles were used, which can improve the powder quality remarkable. But, some yttrium oxide still remained after a calcination at a temperature of $1300{ }^{\circ} \mathrm{C}$ after 5 cycles and a temperature of $1400{ }^{\circ} \mathrm{C}$ after 3 cycles. If the calcination temperature is further increased up to $1500{ }^{\circ} \mathrm{C}$, a pure YSH phase can be obtained. In this case, only 1 cycle is needed (Fig. 1c). However, a pure phase YSH powder can be obtained after one milling cycle followed by a calcination at $1300{ }^{\circ} \mathrm{C}$ when using water-based milling method. Such a $200{ }^{\circ} \mathrm{C}$ difference should be attributed to the improved oxide powder mixture homogeneity. As a common knowledge, alcohol is always recommended as the standard dispersant for most powder materials, but it is clear that the low surface tension provided by alcohol is still not good enough for delicate request in homogeneous mixing. It is necessary to provide extra mechanism, such as electrostatic stabilization, to promise a good mixing state when multi- 
component system is studied. It can be easily realized by adjusting $\mathrm{pH}$ value of water-based milling medium. In addition, the cooling rate can also influence the phase structure (Fig. 1d). The main composition of the obtained powder is $\mathrm{HfO}_{2}$ and $\mathrm{Hf}_{2} \mathrm{Y}_{2} \mathrm{O}_{7}$, when a lower cooling rate was used (around $5{ }^{\circ} \mathrm{C}$, same as heating process rate). In contrast, the pure designed $\mathrm{Hf}_{0.69} \mathrm{Y}_{0.31} \mathrm{O}_{2-\delta}(\mathrm{YSH})$ can be obtained when a fast cooling rate (more than $25^{\circ} \mathrm{C}$ ) was used. Thus, it is important to choose a fast cooling rate to get a pure phase YSH. Based on this, water-based milling method and a fast cooling rate were chosen in the following experiment.
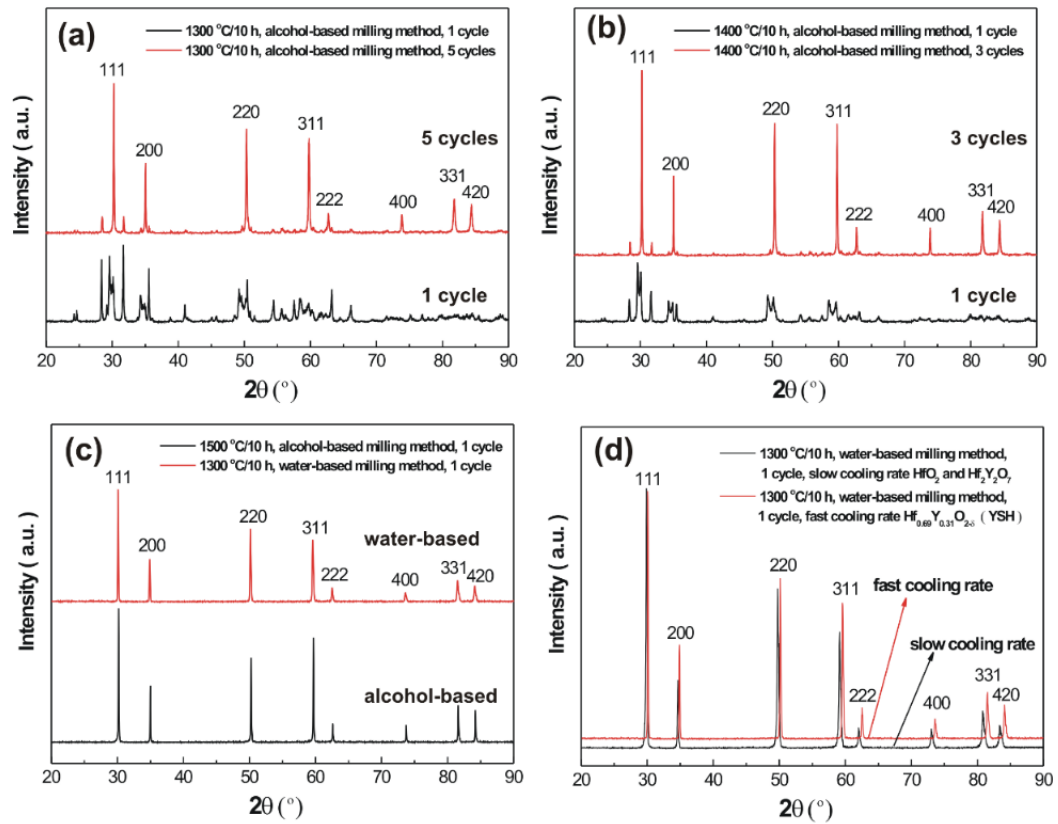

Figure 1. XRD patterns of synthesized powders by alcohol-based milling method calcined at (a) $1300{ }^{\circ} \mathrm{C}$, (b) $1400{ }^{\circ} \mathrm{C}$ and (c) $1500{ }^{\circ} \mathrm{C}$. Also, XRD data is shown for synthesized powders prepared by the water-based milling method that calcined at (c) $1300{ }^{\circ} \mathrm{C}$ and (d) $1300{ }^{\circ} \mathrm{C}$ but using a different cooling rate.

\section{$\underline{\text { SEM analysis }}$}

The sizes and morphologies of the obtained YSH powders show big differences when using different preparation methods. The YSH particles, prepared by the alcohol-based milling method, have an irregular shape and the mean size is more than 1 um (Fig. 2a). However, the mean size of an YSH powder, prepared by water-based milling method, can be lower to nano-scale (around $100 \mathrm{~nm}$ ) (Fig. 2b). But, part of particles will be agglomerated into a big particle after calcination. Thus, it is better to milled again by using the water-based milling method to get better dimensional homogeneity. Based on XRD and SEM results, it is proven that the water-based milling method followed by freeze dying process can improve the quality of the powder significantly.

Currently, the solid state reaction method is still the main used method for the preparation of ceramic materials. Despite the advantage of its low manufacturing cost and simplicity, it usually requires multiple repetitions of prolonged thermal treatments and grindings to reach satisfactorily results. This is also confirmed by the XRD results in this study (Fig. 1a-b). As a consequence, an uncontrolled crystalline growth can occur. This, in turn, could induce chemical and grain-size non-uniformities (Fig. 2a).

Alcohol is recommended as the standard dispersant for most powder materials, but it is clear that the low surface tension provided by alcohol is still not good enough for adequate 
homogeneous mixing. In this work, organic binders were used in the water-based milling method, which is followed by freeze-drying. This method can provide a better electrostatic stabilization through simply adjusting the $\mathrm{pH}$ value to 10 . The milling slurry was firstly frozen by liquid nitrogen. Then, the surrounding pressure was reduced to allow the frozen water in the precursor to sublimate directly from the solid phase to the gas phase. By using the simple freeze and sublimation processes, the uniform state in a solution could be retained to obtain precursors which have been mixed at an atomic level. Besides this, the calcination temperature can be lowered several hundred degrees. Also, an improved sintering behaviour and properties have also been reported in previous research (35-41).
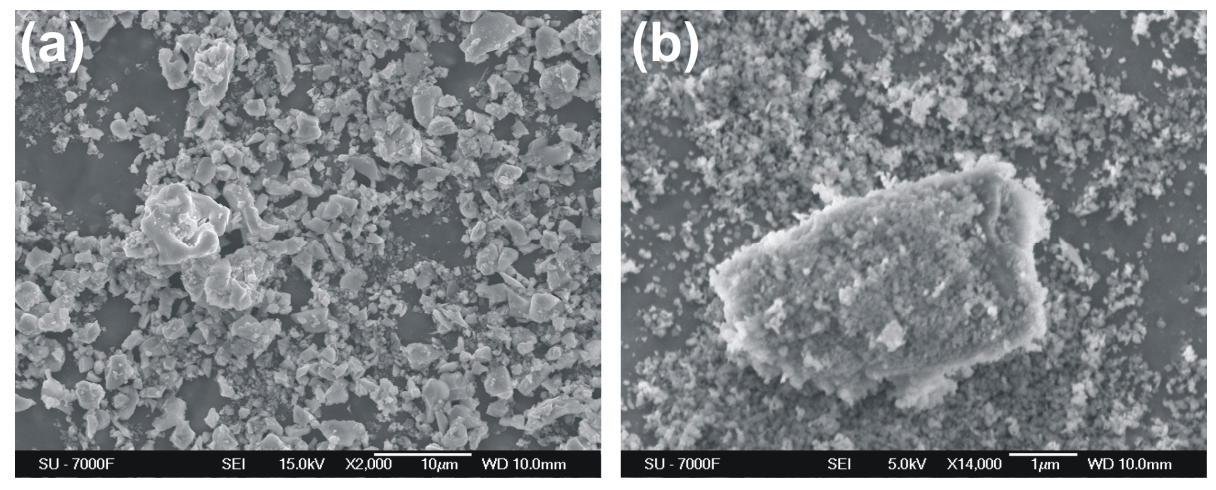

Figure 2. The morphologies of powders prepared by (a) the alcohol-based solid state reaction method with a calcination temperature of $1500{ }^{\circ} \mathrm{C}$, (b) the modified water-based solid state reaction method with a calcination temperature of $1300^{\circ} \mathrm{C}$.

\section{$\underline{\text { Relative density analysis }}$}

A dense pellet is needed for solid oxide fuel cells application. Fig. 3 shows the influence of compaction pressure on the final relative density. It is clear that an increased compaction stress will lead to a rapid increase in the final relative density. More specifically, the relative density is only $74.6 \%$ when a pressure of $100 \mathrm{MPa}$ was used. However, the relative density can increase linearly to $96.3 \%$ when a $400 \mathrm{MPa}$ pressure was used. If the pressure is further increased up to $500 \mathrm{MPa}$, only a gentle $1.2 \%$ increasement is obtained (reach to $97.5 \%$ ). In addition, the green body starts to crack if the pressure continue to increase to a value higher than 500 MP. In order to get the dense pellet for a conductivity test, a $500 \mathrm{MPa}$ pressure is used for the pellet preparation. Also, it is sintered by the conventional sintering method.

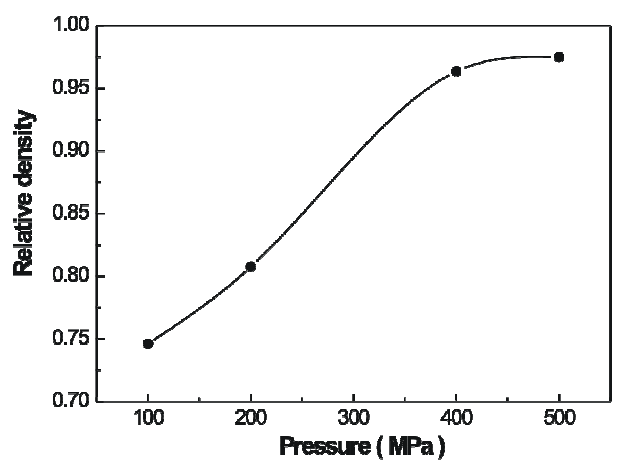

Figure 3. The effect of compaction stress on the final relative densities of YSH pellets sintered at $1650{ }^{\circ} \mathrm{C}$ for 10 $\mathrm{h}$ using the conventional sintering method. 


\section{Conclusions}

Water-based milling method can improve the powder quality significantly compared to the conventional alcohol-based method. A pure and well crystalized YSH powder can be obtained by the alcohol-based milling method after calcination at a temperature of $1500{ }^{\circ} \mathrm{C}$ and $1300{ }^{\circ} \mathrm{C}$ by the using water-based milling method along with a fast cooling rate. Besides the $200{ }^{\circ} \mathrm{C}$ lower calcination temperature, the mean size of the prepared YSH, using the waterbased milling method, can be reduced from micro-meters (more than $1 \mathrm{um}$ ) to nano-meters (around $100 \mathrm{~nm}$ ). Moreover, the homogeneity is higher when using the water-based milling method. In addition, the relative density of an YSH ceramic material can reach to $97.5 \%$ by conventional sintering at $1650{ }^{\circ} \mathrm{C}$ for $10 \mathrm{~h}$. The modified solid state reaction method can also be extended to the fabrication of other difficult sintered materials. Finally, it should be mentioned that the oxygen ion conductivity and protonic conductivity of YSH pellets will be further studied in following research work.

\section{Acknowledgments}

The authors declare that they have no competing conflict interests. The authors would like to acknowledge the financial support through Olle Eriksson Foundation Scholarship at KTH and Program for Professor of Special Appointment (Eastern Scholar) at Shanghai Institutions of Higher Learning.

\section{References}

1. J. Adam and M. Rogers, Acta Crystallographica, 12, 951 (1959).

2. E. R. Andrievskaya, J. Eur. Ceram. Soc., 28, 2363 (2008).

3. T. Etsell and S. N. Flengas, Chemical Reviews, 70, 339 (1970).

4. E. Subbarao, Advances in ceramics, 1, 1 (1981).

5. D. Janke and W. Fischer, Archiv fur das Eisenhuttenwesen, 45, 477 (1975).

6. S. S. Pandit, A. Weyl and D. Janke, Solid State Ionics, 69, 93 (1994).

7. H. Hufschmidt, A. Weyl and D. Janke, J. Am. Ceram. Soc., 79, 756 (1996).

8. M. van Wijngaarden and J. Geldenhuis, Iron Steelmaker, 15, 35 (1988).

9. M. Iwase, E. Ichise, M. Takeuchi and T. Yamasaki, T. Jpn. I. Met., 25, 43 (1984).

10. D. Ding, M. Y. Gong, C. C. Xu, N. Baxter, Y. H. Li, J. Zondlo, K. Gerdes, X. B. Liu, J. Power Sources, 196, 2551 (2011).

11. J. S. Cronin, J. R. Wilson and S. A. Barnett, J. Power Sources, 196, 2640 (2011).

12. K. C. Wincewicz and J. S. Cooper, J. Power Sources, 140, 280 (2005).

13. F. Yang, X. Zhao and P. Xiao, J. Power Sources, 196, 4943 (2011).

14. J. W. Fergus, J. Power Sources, 162, 30 (2006).

15. H. Johansen and J. Cleary, J. Electrochem. Soc., 111, 100 (1964).

16. J. D. Schieltz, J. W. Patterson and D. Wilder, J. Electrochem. Soc., 118, 1257 (1971).

17. A. Weyl and D. Janke, J. Am. Ceram. Soc., 79, 2145 (1996).

18. Y. Saito, T. Maruyama and Z. Kato, Zeitschrift für Physikalische Chemie, 135, 201 (1983).

19. E. Fabbri, D. Pergolesi and E. Traversa, Chem. Soc. Rev., 39, 4355 (2010).

20. E. Fabbri, L. Bi, D. Pergolesi and E. Traversa, Adv. Mater., 24, 195 (2012). 
21. D. Medvedev, A. Murashkina, E. Pikalova, A. Demin, A. Podias and P. Tsiakaras, Progress in Materials Science, 60, 72 (2014).

22. P. Babilo and S. M. Haile, J. Am. Ceram. Soc., 88, 2362 (2005).

23.Y. Nigara, K. Yashiro, J. O. Hong, T. Kawada and J. Mizusaki, Solid State Ionics, 171, 61 (2004).

24. B. Scherrer, M. V. F. Schlupp, D. Stender, J. Martynczuk, J. G. Grolig, H. Ma, P. Kocher, T. Lippert, M. Prestat and L. J. Gauckler, Adv. Funct. Mater., 23, 1957 (2013).

25. X. Guo, E. Vasco, S. Mi, K. Szot, E. Wachsman and R. Waser, Acta Mater., 53, 5161 (2005).

26.Y. Nigara, K. Yashiro, T. Kawada and J. Mizusaki, Solid State Ionics, 159, 135 (2003).

27. C. Tandé, D. Pérez-Coll, G.C. Mather, J. Mater. Chem., 22, 11208 (2012).

28. M. Shirpour, G. Gregori, R. Merkle and J. Maier, Phys. Chem. Chem. Phys., 13, 937 (2011).

29. H. J. Avila-Paredes, E. Barrera-Calva, H. U. Anderson, R. A. De Souza, M. Martin, Z. A. Munir and S. Kim, J. Mater. Chem., 20, 6235 (2010).

30. H. Takamura and N. Takahashi, Solid State Ionics, 181, 100 (2010).

31. H. J. Avila-Paredes, C. T. Chen, S. Wang, R. A. De Souza, M. Martin, Z. Munir, S. Kim, J. Mater. Chem., 20, 10110 (2010).

32. E. Ruiz-Trejo and J. A. Kilner, J. Appl. Electrochem., 39, 523 (2009).

33. S. Kim, H. J. Avila-Paredes, S. Wang, C. T. Chen, R. A. De Souza, M. Martin and Z. A. Munir, Phys. Chem. Chem. Phys., 11, 3035 (2009).

34. G. Chiodelli, F. Maglia, U. Anselmi-Tamburini and Z. A. Munir, Solid State Ionics, 180, 297 (2009).

35. D. Marrero-Lopez, J. C. Ruiz-Morales, P. Nunez, J. C. C. Abrantes and J. R. Frade, J. Solid State Chem., 177, 2378 (2004).

36.X. Zhang, H. Z. Zhao, Q. Ma, X. W. Li, H. Z. Wang and W. J. Zhang, Rare Metal Mat. Eng., 34, 78 (2005).

37. S. Ivanova, E. Zhecheva and R. Stoyanova, J. Phys. Chem. Solids, 68,168 (2007).

38.V. Palomares, A. Goni, L. G. de Muro, I. de Meatza, M. Bengoechea, O. Miguel and T. Rojo, J. Power Sources, 171, 879 (2007).

39. O. A. Shlyakhtin, G. N. Mazo, S. A. Malyshev, L. N. Kolchina, A. V. Knotko, A. S. Loktev and A. G. Dedov, Mater. Res. Bull., 48, 245 (2013).

40. V. Primo-Martin and M. Jansen, J. Solid State Chem., 157, 76 (2001).

41. A. Watcharapasorn, P. Siriprapa and S. Jiansirisomboon, J. Eur. Ceram. Soc., 30, 87 (2010). 